\title{
Development of a Polymer Inclusion Membrane Incorporated in a Microfluidic Paper-Based Sensor for the Determination of $\mathrm{Cu}(\mathrm{II})$
}

\author{
Leonardo N. Sibal' ${ }^{1}$, Razelle Angela B. Camitan², Dan Alfonso O. Yabut'2, Bryan A. Rivera² \\ and Lilibeth dIC. Coo ${ }^{1, *}$ \\ 1 Institute of Chemistry, University of the Philippines, Diliman, Quezon City, 1101, Philippines \\ 2 Philippine Council for Industry, Energy and Emerging Technology Research and Development \\ (PCIEERD), Department of Science and Technology, Science Community Complex, Bicutan, Taguig \\ City, 1631, Philippines \\ Corresponding author's e-mail address: Idcoo@up.edu.ph
}

\begin{abstract}
A polymer inclusion membrane (PIM) incorporated in a microfluidic paper-based sensor ( $\mu$ PBS) was prepared for the optical determination of copper in water samples. The PIM composition needed to achieve high selectivity and sensitivity for the analytical determination of $\mathrm{Cu}(\mathrm{II})$ ions was optimized. It was composed of $8 \mathrm{wt} \%$ dioctyl phthalate, $51.5 \mathrm{wt} \%$ poly(vinyl chloride), $40 \mathrm{wt} \%$ di-(2-ethylhexyl) phosphoric acid and $0.5 \mathrm{wt} \%$ 2-(2-thiazolylazo)-p-cresol (TAC). TAC reacts with $\mathrm{Cu}(\mathrm{II})$ producing a green-colored complex. The $\mu$ PBS was produced by laminating a stack of the PIM and two layers of preconditioned filter paper. High reactivity and selectivity of the $\mu$ PBS was observed at $\mathrm{pH}$ 3.0. The proposed method has a limit of detection (LOD) of $0.05 \mathrm{mg} / \mathrm{L}$ and a limit of quantitation (LOQ) of 0.16 $\mathrm{mg} / \mathrm{L}$. The optimized $\mu \mathrm{PBS}$ was successfully used in determining the $\mathrm{Cu}(\mathrm{II})$ concentrations in river water samples with no significant difference from results obtained using atomic absorption spectroscopy.
\end{abstract}

Key words: microfluidic paper-based sensor; polymer inclusion membrane; heavy metals analysis; environmental samples; optode

\begin{abstract}
Introduction
Developing countries are more likely to be at risk of being exposed to heavy metals through water intake as they usually lack more advanced techniques in the treatment and sequestration of heavy metals due to lack of facilities [1]. Thus, there is a need to monitor $\mathrm{Cu}$ (II) concentrations especially in communities near mining sites where large volumes of wastes are being dumped, contaminating the nearby rivers with heavy metals like $\mathrm{Cu}(\mathrm{II})$.
\end{abstract}

Polymer inclusion membrane (PIM) is composed of a base polymer, a plasticizer, an ionic or organic extracting agent typically called carrier and a colorimetric agent. All these components of PIM provide the selectivity and sensitivity needed for $\mathrm{Cu}(\mathrm{II})$ quantitation. In this study, $\mathrm{Cu}$ (II) concentrations were determined using PIM. The PIM to be used is composed of dioctyl phthalate (DOP) as plasticizer, poly(vinyl chloride) (PVC) as the base polymer, di-(2ethylhexyl) phosphoric acid (D2EHPA) as the carrier and 2-(2-thiazolylazo)-p-cresol (TAC) as the colorimetric probe. A microfluidic paper-based sensor ( $\mu$ PBS) was fabricated by incorporating PIM in a modified filter paper containing hydrophobic and hydrophilic zones that served as reaction vessel for $\mathrm{Cu}$ (II) sensing. The $\mathrm{Cu}(\mathrm{II})$ sensing was carried out by the formation of $\mathrm{Cu}$-TAC complex, which changes the color of PIM from orange to green. The color intensity was then optically measured to calculate for the concentration of $\mathrm{Cu}(\mathrm{II})$.

\section{Experimental Design}

PIM was prepared by dissolving a total of $0.7 \mathrm{~g}$ of D2EHPA, DOP, PVC and TAC in $7.5 \mathrm{~mL}$ of tetrahydrofuran (THF). After mixing for 2 hours, the solution was poured into a 7.5-inch diameter glass ring sitting on a flatglass. The THF was allowed to evaporate for $48 \mathrm{hrs}$ or until dry at room temperature.

Hydrophobic zone patterns were printed in a Whatman Grade 4 filter paper using a printer with a customized cartridge containing alkyl ketene dimer [2]. Hydrophilic zones were then acidified dropwise with a predetermined $\mathrm{pH}$. Circular PIMs were placed in the center of the hydrophilic zones. The whole stack was then laminated using an ethylene vinyl acetate-based laminating film (Fig.1). Finally, $2 \mathrm{~mm}$ diameter holes were punched in the plastic cover of the rear part of the final $\mu P B S$ which served as standard/sample introduction port [3]. The proposed $\mu$ PBS has a size of $165 \mathrm{~mm} \times 210 \mathrm{~mm}$.

Standard/sample $(15 \mu \mathrm{L})$ was introduced to the punched hole. After this, the PIM color intensity was scanned using a scanner. The RGB color intensity profile plot was obtained for every PIM using the program ImageJ (National Institutes of Health, USA, http://imagej.nih.gov/ij). The absorbance was 
calculated as the negative base 10 logarithm of the ratio between the color intensity of the reacted PIM and the blank PIM.

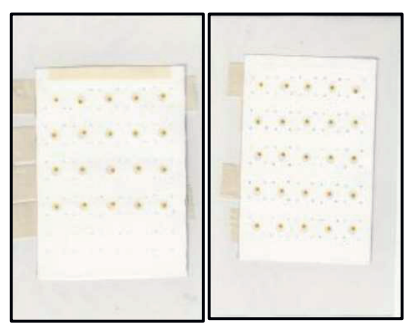

Fig. 1. Scanned images of unreacted (left) and reacted (right) microfluidic paper-based sensor.

\section{Results and discussion}

The concentration of TAC in the PIM greatly affected the absorbance values of the $\mu$ PBS because too much or too little of it gave erroneous measurements. From studies by Baba et. al. [4] and Rerkpalin [5], D2EHPA extracts metals preferentially at acidic solutions and TAC forms a stable 1:1 green complex with $\mathrm{Cu}(\mathrm{II})$ at acidic solutions. Therefore, another factor that was considered for $\mu$ PBS optimization is the effect of hydrophilic zone acidity of the 2-layer $\mu$ PBS. The list of optimized parameters for the $\mu \mathrm{PBS}$ is presented in Table 1.

Tab. 1. Optimized parameters of the proposed $\mu$ PBS.

\begin{tabular}{|l|c|}
\hline Parameter & Optimal Value \\
\hline PVC (wt\%) & 51.5 \\
\hline DOP (wt\%) & 8 \\
\hline D2EHPA (wt\%) & 40 \\
\hline TAC (wt\%) & 0.5 \\
\hline Sample volume $(\mu \mathrm{L})$ & 15 \\
\hline pH & 3.0 \\
\hline $\begin{array}{l}\text { Color development time } \\
\text { (min) }\end{array}$ & 30 \\
\hline
\end{tabular}

Interference studies for $\mathrm{Zn}(\mathrm{II}), \mathrm{Mg}(\mathrm{II}), \mathrm{Ca}(\mathrm{II}), \mathrm{Fe}(\mathrm{III})$, $\mathrm{Al}(\mathrm{II})$ and $\mathrm{Co}(\mathrm{II})$ did not exhibit interference signal by more than $5 \%$. However, $\mathrm{Ni}(\mathrm{II})$ exhibited $14 \%$ interference, $\mathrm{Cd}(\mathrm{II})$ exhibited $27 \%$ interference and $\mathrm{Pb}$ (II) exhibited $47 \%$ interference with $\mathrm{Cu}(\mathrm{II})$. $\mathrm{Ni}(\mathrm{II})$ usually exists in drinking and natural waters at $\mu \mathrm{g} / \mathrm{L}$ concentrations [3]. Burger [7] listed possible masking agents for metal ions, and suggested that $\mathrm{Pb}(\mathrm{II})$ interference may be suppressed using iodide solution, while $\mathrm{Cd}(\mathrm{II})$ interference may be suppressed by using cyanide solution. The lower calibration curve for the concentrations in the range of 0.1 to $1.0 \mathrm{mg} / \mathrm{L}$ achieved a correlation factor of 0.9958 . The LOD for the method is computed as $0.05 \mathrm{mg} / \mathrm{L}(\mathrm{n}=8)$ and the $L O Q$ for the method is $0.16 \mathrm{mg} / \mathrm{L}(\mathrm{n}=8)$.

To validate the analytical performance of this method, water samples collected from a river near mining sites in Benguet, Philippines were analyzed using AAS and the proposed $\mu$ PBS. The results are summarized in Table 2.

Tab. 2. Comparison of concentration of $\mathrm{Cu}$ (II) obtained from $\mu P B S$ method and AAS method.

\begin{tabular}{|l|l|l|l|l|}
\hline Sample & $\begin{array}{l}\mathrm{C}_{\text {AAS, }} \\
\mathrm{mg} / \mathrm{L}\end{array}$ & $\mathrm{SD}_{\mathrm{AAS}}$ & $\begin{array}{l}\mathrm{C}_{\mu \mathrm{PBS}}, \\
\mathrm{mg} / \mathrm{L}\end{array}$ & $\mathrm{SD}_{\mu \mathrm{PBS}}$ \\
\hline $\begin{array}{l}\text { River } \\
\text { Sample 1 }\end{array}$ & 0.60 & $\begin{array}{l}0.02 \\
(\mathrm{n}=2)\end{array}$ & 0.4 & $\begin{array}{l}0.1 \\
(\mathrm{n}=3)\end{array}$ \\
\hline $\begin{array}{l}\text { River } \\
\text { Sample 2 }\end{array}$ & 0.565 & $\begin{array}{l}0.001 \\
(\mathrm{n}=2)\end{array}$ & 0.5 & $\begin{array}{l}0.1 \\
(\mathrm{n}=3)\end{array}$ \\
\hline
\end{tabular}

\section{Conclusion}

A microfluidic paper-based sensor for $\mathrm{Cu}(\mathrm{II})$ using polymer inclusion membrane was developed in this study. The PIM used for the $\mu$ PBS reacted with $\mathrm{Cu}$ (II) in acidic medium to produce a green complex that can be quantified optically by readily available electronic devices like a flatbed scanner. The incorporation of TAC in the PIM makes this study a novel PIM application for metal analysis. River water samples collected exceeded the $0.02 \mathrm{mg} / \mathrm{L}$ limit set by the Philippine Department of Environment and Natural Resources [6].

\section{References}

[1] Chowdhury, S., Mazumder, M. A. J., Al-Attas, O., Husain, T. (2016). Heavy metals in drinking water: Occurrences, implications, and future needs in developing countries. Science of Total Environment. 569-570, pp. 476-488M.

[2] Li, X., Tian, J., Nguyen, T., Shen, W., (2010). Fabrication of paper-based microfluidic sensors by printing. Colloids and Surfaces B: Biointerfaces. 76, pp.564-570

[3] Jayawardane, B.M., Coo, L. dIC., Cattrall, R.W., Kolev, S.D., (2013). The use of a polymer inclusion membrane in a paper-based sensor for the selective determination of $\mathrm{Cu}(\mathrm{II})$. Analytica Chimica Acta. 803, pp.106-112

[4] Y. Baba, K. Hoaki, J.M. Perera, G.W. Stevens, T.J. Cardwell, R.W. Cattrall, S.D. Kolev, Separation of palladium(II) from copper(II) acidic solutions using PVC membranes containing D2EHPA, Chim. Anal. 54(10) (2001) 69-72.

[5] Rerkpalin, W. Complex Formation of 2- (2thiazolylazo)-p-cresol and Its Applications as Chelating Reagent for Cadmium (II) and Copper (II). Retrieved August 19, 2017.

[6] DENR Administrative Order No. 2016-08. (2016) Water Quality Guidelines and Effluent Standards of 2016. [ONLINE] Available at:

http://server2.denr.gov.ph/uploads/rmdd/dao2016-08.pdf

[7] Burger, K. (1973). Organic Reagents in Metal Analysis. Budapest, Hungary: Pergamon Press Ltd., Akademiai Kiado 